\title{
Moraxella porci sp. nov., isolated from pigs
}

\author{
Correspondence \\ J. F. Fernández-Garayzábal \\ garayzab@vet.ucm.es
}

\section{A. I. Vela, ${ }^{1,2}$ C. Sánchez-Porro, ${ }^{3}$ V. Aragón, ${ }^{4}$ A. Olvera, ${ }^{4}$ L. Domínguez, ${ }^{1,2}$ A. Ventosa ${ }^{3}$ and J. F. Fernández-Garayzábal ${ }^{1,2}$}

\author{
${ }^{1}$ Centro de Vigilancia Sanitaria Veterinaria (VISAVET), Universidad Complutense, Madrid, Spain \\ ${ }^{2}$ Departamento de Sanidad Animal, Facultad de Veterinaria, Universidad Complutense, Madrid, \\ Spain \\ ${ }^{3}$ Departamento de Microbiología y Parasitología. Facultad de Farmacia. Universidad de Sevilla. \\ 41012 Sevilla, Spain \\ ${ }^{4}$ Centre de Recerca en Sanitat Animal (CReSA), Campus de Bellaterra-Universitat Autónoma de \\ Barcelona, 08193-Bellaterra, Barcelona, Spain
}

\begin{abstract}
Nine Gram-negative, catalase- and oxidase-positive, coccus-shaped bacteria were isolated from pigs affected by different pathological processes. Phenotypic and genotypic methods were adopted to determine the relationships of these new isolates to recognized species of the genus Moraxella. Analysis of the 16S rRNA gene sequences demonstrated that the clinical isolates represented a new lineage within the genus Moraxella. The isolates were closely related to Moraxella cuniculi and Moraxella pluranimalium with 16S rRNA gene sequence similarities of $98.1 \%$ and $99.1 \%$, respectively. The isolates displayed DNA-DNA relative binding ratios of $74 \%$ to each other, but distinctly lower levels of DNA-DNA hybridization were observed with phylogenetically closely related moraxellae $(<32 \%)$. The new isolates could be distinguished from all other recognized species of the genus Moraxella by physiological and biochemical tests. On the basis of the phenotypic and molecular data, the nine new isolates from pigs represent a novel species within the genus Moraxella, for which the name Moraxella porci sp. nov. is proposed. The type strain is SN9-4M ${ }^{\top}$ (=CECT $7294^{\top}=$ CCUG $54912^{\top}$ ).
\end{abstract}

The genus Moraxella currently comprises 21 species with validly published names (http://www.bacterio.net; Juni \& Bøvre, 2005), some of which have been described during the last decade (Angelos et al., 2007; Vela et al., 2009). The recognition of these novel species has been made possible by the use of improved taxonomic methods, such as chemotaxonomic- and molecular-based approaches, especially $16 \mathrm{~S}$ rRNA gene sequencing. Although some of the members of the genus Moraxella have been isolated from animal sources, most of them are usually found as part of the indigenous microbiota of animals (Kodjo et al., 1995, 1997; Juni \& Bøvre, 2005) and are not considered of clinical relevance in veterinary medicine. In fact, only Moraxella bovis is a well-established animal pathogen, being responsible for ocular and respiratory infections (Brown et al., 1998; Quinn et al., 1999; Lavin et al., 2000). In this study, we characterized nine Moraxella-like organisms isolated from different clinical specimens from pigs during routine microbiological diagnosis.

Unidentified Gram-negative coccus-shaped organisms were isolated from different clinical specimens of nine pigs

The GenBank/EMBL/DDBJ accession number for the 16S rRNA gene sequence of strain SN9-4MT is FM872292. located in seven farms. Isolates 466-01 and 1335-02 were isolated from the pleura of two pigs with pleuritis. Isolates 1407-02 and 91-02 were isolated from the lungs of two pigs with pneumonia. Isolates 43-02, 464-01 and N148-05CP$52 \mathrm{G}$ were isolated from the pericardium of three pigs affected by pericarditis. Isolate SN9-4M $\mathrm{M}^{\mathrm{T}}$ and isolate 1008 04 were from the brain and an inguinal lymph node of two pigs with meningitis and inguinal adenomegaly, respectively. Samples were collected and frozen at $-40{ }^{\circ} \mathrm{C}$ until processed in the laboratory. Strains were isolated on Columbia sheep blood agar plates (bioMérieux) after incubation at $37{ }^{\circ} \mathrm{C}$ for $24-48 \mathrm{~h}$ under aerobic conditions. The new isolates were Gram-stained and assessed for the presence of oxidase and catalase as described by Barrow \& Feltham (1993). DNA hydrolysis was tested by using DNase test agar. Growth in brain heart infusion broth was assessed at 4 and $15{ }^{\circ} \mathrm{C}$ for up to 14 days, at $22{ }^{\circ} \mathrm{C}$ for up to 7 days and at 30,37 and $42{ }^{\circ} \mathrm{C}$ for $48 \mathrm{~h}$. Growth in the presence of $0.5,1.5,3,4$ and $6.5 \%(\mathrm{w} / \mathrm{v}) \mathrm{NaCl}$ and under anaerobic (with 4-10\% $\mathrm{CO}_{2}$ ) and microaerobic (with 5-15\% $\mathrm{O}_{2}$ and 5-12\% $\mathrm{CO}_{2}$ ) conditions, using GasPak Plus and CampyPak Plus systems (BBL), respectively, was assessed at $37{ }^{\circ} \mathrm{C}$ for $48 \mathrm{~h}$. Growth on MacConkey agar (bioMérieux) and chocolate agar (bioMérieux) was tested at $37^{\circ} \mathrm{C}$ for 24 and $48 \mathrm{~h}$. Additional biochemical tests were performed by using the 
API 20NE, API 20E and API ZYM systems (bioMérieux) and Biolog GN Microplates (Biolog, Inc.) according to the manufacturer's instructions, except that incubation conditions for API 20NE tests were $37^{\circ} \mathrm{C}$ for $72 \mathrm{~h}$. Phenotypic studies were also carried out with the reference strains Moraxella pluranimalium $248-01^{\mathrm{T}}$, Moraxella cuniculi CCUG $2154^{\mathrm{T}}$, Moraxella caprae CCUG $33296^{\mathrm{T}}$, Moraxella bovis CCUG $2133^{\mathrm{T}}$ and Moraxella canis CCUG $26883^{\mathrm{T}}$.

The nine new isolates exhibited identical phenotypic characteristics, except for the assimilation of gluconate (isolate 1335-02 was positive), malate (isolates 1335-02, 1407-02 and 43-02 were negative), methyl pyruvate (isolate $\mathrm{SN} 9-4 \mathrm{M}^{\mathrm{T}}$ was negative), monomethyl succinate (isolates $1335-02,43-02, \quad 1008-04$ and N148-05CP-52G were negative) and succinic acid (isolate 1008-04 was negative), growth in the presence of $3 \%(\mathrm{w} / \mathrm{v}) \mathrm{NaCl}$ (isolates 91-02, 466-01, 1008-04 and 1335-02 did not grow) and reduction of nitrate (isolates 43-02 and 1407-02 were negative). A detailed presentation of the morphological, physiological and biochemical characteristics of the isolates is given in the species description and in Table 1.

To establish the phylogenetic affinities of the new isolates, their 16S rRNA gene sequences were determined as described previously (Vela et al., 2005) and subjected to a comparative analysis. The almost complete sequences of the nine new strains were determined and pairwise analysis revealed 99.4-100\% 16S rRNA gene sequence similarity among the isolates. Sequence searches of GenBank using the FASTA program (Pearson, 1994) showed that the new isolates were most closely related to members of the genus Moraxella. Strain SN9-4M ${ }^{\mathrm{T}}$ displayed the closest $16 \mathrm{~S}$ rRNA gene sequence similarity to $M$. pluranimalium $248-01^{\mathrm{T}}$ ( $99.1 \%$ sequence similarity) and $M$. cuniculi CCUG $2154^{\mathrm{T}}$ ( $98.1 \%$ sequence similarity). These sequences and those of other known related strains were retrieved from GenBank and aligned with the newly determined sequences using the DNATools program (Rasmussen, 1995). Phylogenetic trees were constructed according to three different algorithms: neighbour-joining (Saitou \& Nei, 1987), using the DNATools and TreeView programs (Page, 1996), maximumlikelihood, using PHYML software (Guindon \& Gascuel, 2003), and maximum-parsimony, using the MEGA (molecular evolutionary genetics analysis) version 3.1 software package (Kumar et al., 2004). Phylogenetic distances for the neighbour-joining and the maximum-likelihood algorithms were calculated by the Kimura two-parameter method (Kimura, 1980) and close-neighbour-interchange (search level $=2$, random additions $=100$ ) was applied in the maximum-parsimony analysis. The stability of the groupings was estimated by bootstrap analysis (1000 replications). The topology of the phylogenetic trees obtained by using the neighbour-joining and the other two methods revealed a clear affiliation of the new isolates to the genus Moraxella and placed them as a separate branch within an intrageneric cluster containing $M$. cuniculi CCUG $2154^{\mathrm{T}}$ and $M$. pluranimalium $248-01^{\mathrm{T}}$, which was supported by a bootstrap resampling value of $99 \%$.
Table 1. Characteristics that are useful for differentiating the novel strains from phylogenetically closely related species of the genus Moraxella

Taxa: 1, M. porci sp. nov. (nine strains); 2, M. pluranimalium $248-01^{\mathrm{T}}$; 3, M. cuniculi CCUG $2154^{\mathrm{T}}$; 4, M. bovis CCUG $2133^{\mathrm{T}}$; 5 , M. canis CCUG $26883^{\mathrm{T}} ; 6$, M. caprae CCUG $33296^{\mathrm{T}}$. Phenotypic data for $M$. porci sp. nov. and for the other species of the genus Moraxella were taken from this study. +, Positive; -, negative; C, coccus; R, rod.

\begin{tabular}{|c|c|c|c|c|c|c|}
\hline Characteristic & 1 & 2 & 3 & 4 & 5 & 6 \\
\hline Morphology & C & C & C & $\mathrm{R}$ & C & $\mathrm{R}$ \\
\hline Tolerance of $3 \% \mathrm{NaCl}$ & $\mathrm{V}^{*}$ & - & - & + & + & + \\
\hline Growth at $42{ }^{\circ} \mathrm{C}$ & + & - & + & - & + & - \\
\hline Haemolysis & - & - & - & + & + & + \\
\hline Nitrate reduction & $v^{*}$ & - & - & + & + & - \\
\hline \multicolumn{7}{|l|}{ Assimilation of: } \\
\hline Acetic acid & - & - & - & + & + & + \\
\hline cis-Aconitic acid & - & - & - & + & - & - \\
\hline Bromosuccinic acid & - & - & + & + & + & + \\
\hline Citric acid & - & - & - & + & - & - \\
\hline D-Fructose & - & - & - & + & - & - \\
\hline Glucose & - & + & - & - & - & - \\
\hline L-Glutamic acid & - & - & + & + & + & + \\
\hline Glycogen & - & - & - & + & - & - \\
\hline L-Histidine & - & - & - & + & - & - \\
\hline$\alpha$-Hydroxybutyric acid & - & - & - & + & + & + \\
\hline$\beta$-Hydroxybutyric acid & + & + & + & + & - & + \\
\hline Inosine & - & - & + & - & - & - \\
\hline$\alpha$-Ketobutyric acid & - & + & - & + & - & - \\
\hline$\alpha$-Ketovaleric acid & - & - & - & + & - & - \\
\hline L-Proline & - & + & + & - & - & - \\
\hline D-Psicose & - & - & - & + & - & - \\
\hline Putrescine & - & - & + & - & - & - \\
\hline L-Serine & - & - & - & + & + & + \\
\hline Succinamic acid & - & - & - & + & - & + \\
\hline Tween 40 & - & - & - & + & + & - \\
\hline Tween 80 & - & - & - & + & + & - \\
\hline Urocanic acid & - & - & - & - & + & + \\
\hline \multicolumn{7}{|l|}{ Production of: } \\
\hline Acid phosphatase & - & - & - & - & + & - \\
\hline Alkaline phosphatase & - & - & - & - & + & - \\
\hline DNase & - & - & - & - & + & - \\
\hline Gelatinase & - & - & - & + & - & - \\
\hline $\begin{array}{l}\text { Naphthol-AS-BI } \\
\text { phosphohydrolase }\end{array}$ & + & + & - & - & - & - \\
\hline
\end{tabular}

${ }^{*}$ Positive reaction for $M$. porci SN9-4M ${ }^{\mathrm{T}}$.

The new isolates showed high 16S rRNA gene sequence similarities to each other, although they consistently formed two separate branches when using three different treeing algorithms (Fig. 1). DNA-DNA hybridization experiments were carried out between representative isolates of both branches (SN9-4M $\mathrm{M}^{\mathrm{T}}$ and 466-01) and between strain $\mathrm{SN} 9-4 \mathrm{M}^{\mathrm{T}}$ and its closest phylogenetic neighbours, M. cuniculi CCUG $2154^{\mathrm{T}}$ and M. pluranimalium $248-01^{\mathrm{T}}$. DNA was extracted and purified by the 


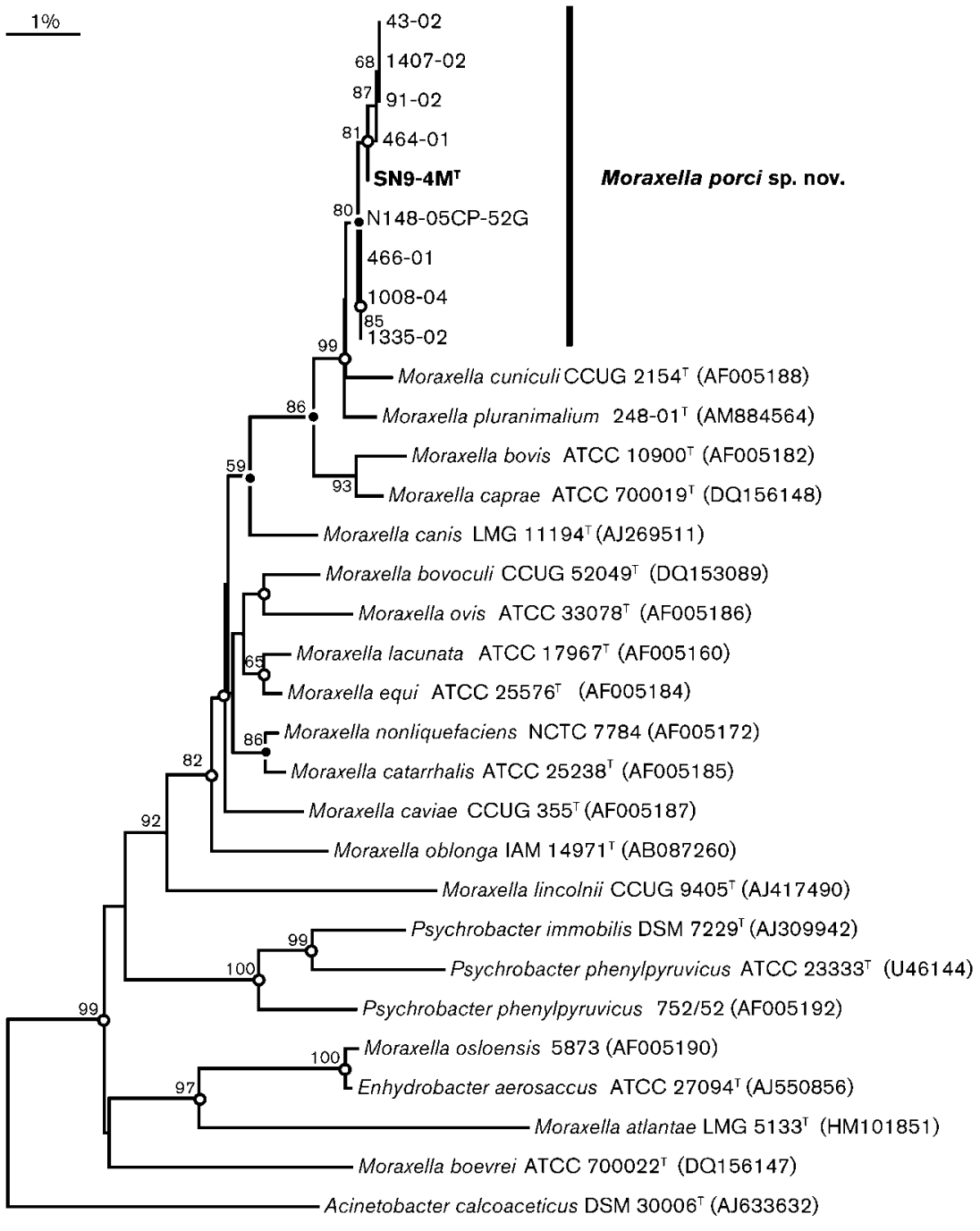

Fig. 1. Phylogenetic tree based on 16S rRNA gene sequence comparisons obtained with the neighbour-joining algorithm showing the relationships of the nine isolates of Moraxella porci $\mathrm{sp}$. nov. and other reference species of the genus Moraxella. Bootstrap values (expressed as a percentage of 1000 replications) $>50 \%$ are given at the branching points. Solid circles indicate that the corresponding nodes (groupings) are also obtained on the parsimony tree. Open circles indicate that the corresponding nodes (groupings) are also obtained on the maximum-likelihood and parsimony trees. Acinetobacter calcoaceticus DSM $30006^{\top}$ (AJ633632) was used as an outgroup. Bar, $1 \%$ sequence divergence. method of Marmur (1961). DNA-DNA hybridization studies were performed according to the competition procedure of the membrane method of Johnson (1994), described in detail by Arahal et al. (2001). The hybridization experiments were carried out under optimal conditions at a temperature of $49.5^{\circ} \mathrm{C}$, which was within the limits of validity for the filter method (De Ley \& Tijtgat, 1970). The percentage of hybridization was calculated as described by Johnson (1994). Three independent determinations were performed for each experiment and the results reported are mean values. The DNA-DNA relatedness between the two representative isolates $\mathrm{SN} 9-4 \mathrm{M}^{\mathrm{T}}$ and $466-01$ was $74 \%$, demonstrating that they were members of the same species (Wayne et al., 1987). The DNA-DNA reassociation values between strain SN9-4M ${ }^{\mathrm{T}}$ and M. cuniculi CCUG $2154^{\mathrm{T}}$ and M. pluranimalium $248-01^{\mathrm{T}}$ were $17 \%$ and $31 \%$, respectively, clearly confirming that the new isolates constituted a separate species (Wayne et al., 1987).

The $\mathrm{G}+\mathrm{C}$ content of the DNA of strain SN9-4M ${ }^{\mathrm{T}}$ was determined from the mid-point value $\left(T_{\mathrm{m}}\right)$ of the thermal denaturation profile (Marmur \& Doty, 1962) obtained with a Perkin-Elmer UV-Vis Lambda 20 spectrophotometer at $260 \mathrm{~nm}$. The $\mathrm{G}+\mathrm{C}$ content of the type strain was $46.6 \mathrm{~mol} \%$. This DNA G $+\mathrm{C}$ content was within the range reported for members of the genus Moraxella (Juni \& Bøvre, 2005).

Overall, the results of the present study showed that the new isolates from pigs constituted a distinct branch within the genus Moraxella (Fig. 1). Moreover, the new isolates could be distinguished from the nearest phylogenetic relatives, $M$. cuniculi and $M$. pluranimalium, and other phylogenetically closely related species of the genus Moraxella on the basis of phenotypic characteristics (Table 1). Given these phenotypic differences and based on phylogenetic and genotypic criteria, it is clear that the new isolates merit classification as a novel species of the genus Moraxella, for which the name Moraxella porci sp. nov. is proposed. Tests which are useful in differentiating M. porci sp. nov. from phylogenetically closely related species of the genus Moraxella are shown in Table 1. 


\section{Description of Moraxella porci sp. nov.}

Moraxella porci (por'ci. L. gen. n. porci of a pig).

Cells are Gram-negative cocci (1-1.5 $\mu \mathrm{m}$ diameter), nonendospore-forming. Catalase-positive, oxidase-positive and aerobic. Colonies are circular, non-pigmented, smooth, entire and do not produce a diagnostic odour on Columbia blood agar after $48 \mathrm{~h}$ incubation at $37^{\circ} \mathrm{C}$. Colonies are non-haemolytic. Growth occurs at $22-42{ }^{\circ} \mathrm{C}$, but not at $15{ }^{\circ} \mathrm{C}$. Growth is enhanced in $5-10 \% \mathrm{CO}_{2}$ (capnophilically) on $5 \%$ sheep blood agar and chocolate agar. Growth does not occur on MacConkey agar. Growth occurs on brain heart infusion broth containing $0.5-1.5 \%(\mathrm{w} / \mathrm{v})$ $\mathrm{NaCl}$, but not with 4 or $6.5 \% \mathrm{NaCl}$. Growth with $3 \% \mathrm{NaCl}$ is variable (positive for strain SN9-4M ${ }^{\mathrm{T}}$ ). With API $20 \mathrm{E}$ and API 20NE kits, aesculin, gelatin and urea are not hydrolysed. Acetoin and indole are not produced (API $20 \mathrm{E}$ ). Acid is not produced from D-glucose, D-mannitol, inositol, D-sorbitol, L-rhamnose, sucrose, melibiose, amygdalin or L-arabinose (API 20E). The following carbon substrates are assimilated (Biolog GN Microplates): methyl pyruvate (SN9-4M ${ }^{\mathrm{T}}$ is negative), $\beta$-hydroxybutyric acid, $\alpha$ ketoglutaric acid, D, L lactic acid and succinic acid. Does not assimilate $\alpha$-D-glucose, citric acid, L-arabinose, D-mannose, D-mannitol, $N$-acetyl-D-glucosamine, maltose, D-gluconic acid, $\alpha$-cyclodextrin, dextrin, glycogen, Tween 40 , Tween 80, D-arabitol, i-erythritol, D-fructose, D-galactose, myoinositol, D-mannitol, D-mannose, D-psicose, D-sorbitol, acetic acid, cis-aconitic acid, citric acid, formic acid, Dgalactonic acid lactone, D-galacturonic acid, D-glucosaminic acid, D-glucuronic acid, $\alpha$-hydroxybutyric acid, $p$ hydroxyphenylacetic acid, $\alpha$-ketobutyric acid, $\alpha$-ketovaleric acid, malonic acid, propionic acid, quinic acid, D-saccharic acid, bromosuccinic acid, succinamic acid, L-alaninamide, D-alanine, L-alanine, L-alanyl glycine, L-asparagine, Laspartic acid, L-glutamic acid, glycyl L-glutamic acid, L-histidine, hydroxy-L-proline, L-leucine, L-ornithine, Lproline, L-pyroglutamic acid, L-serine, L-threonine, DLcarnitine, $\gamma$-aminobutyric acid, urocanic acid, inosine, uridine, 2-aminoethanol, glycerol, DL- $\alpha$-glycerol phosphate, $N$-acetyl-D-galactosamine, cellobiose, melibiose, L-fucose, gentiobiose, $\alpha$-lactose, lactulose, melibiose, methyl $\beta$-Dglucoside, raffinose, L-rhamnose, sucrose, D-trehalose, turanose, xylitol, $\gamma$-hydroxybutyric acid, itaconic acid, sebacic acid, glucuronamide, glycyl L-aspartic acid, Lphenylalanine, D-serine, thymidine, phenylethylamine, putrescine, 2,3-butanediol, glucose 1-phosphate or glucose 6-phosphate (Biolog GN Microplates), phenylacetate, caprate or adipate (API 20NE). Assimilation of malate, monomethyl succinate and reduction of nitrate are variable (SN9-4M $\mathrm{M}^{\mathrm{T}}$ is positive). Activity for ester lipase C8, esterase C4, leucine arylamidase and naphthol-AS-BI-phosphohydrolase is detected (API ZYM). Valine arylamidase, lipase C14, alkaline phosphatase, cystine arylamidase, acid phosphatase, arginine dihydrolase, lysine decarboxylase, ornithine decarboxylase, tryptophan deaminase, $\alpha$-glucosidase, $N$-acetyl- $\beta$-glucosaminidase, $\beta$-glucosidase, $\beta$-glucuronidase, $\alpha$-galactosidase, $\beta$-galactosidase, $\alpha$-mannosidase, $\alpha$-fucosidase, $\alpha$-chymotrypsin and trypsin are not detected (API ZYM).

The type strain, SN9-4M ${ }^{\mathrm{T}} \quad\left(=\mathrm{CECT} \quad 7294^{\mathrm{T}}=\mathrm{CCUG}\right.$ $54912^{\mathrm{T}}$ ), was isolated from the brain of a pig with meningitis. The clinical significance is uncertain. The DNA G + C content of this strain is $46.6 \mathrm{~mol} \%\left(T_{\mathrm{m}}\right)$.

\section{Acknowledgements}

The authors thank E. Arroyo and A. Casamayor for technical assistance. The authors thank Juncal Fernández-Garayzábal for her assistance in reviewing the English of the manuscript.

\section{References}

Angelos, J. A., Spinks, P. Q., Ball, L. M. \& George, L. W. (2007). Moraxella bovoculi sp. nov., isolated from calves with infectious bovine keratoconjunctivitis. Int J Syst Evol Microbiol 57, 789-795.

Arahal, D. R., Garcia, M. T., Vargas, C., Canovas, D., Nieto, J. J. \& Ventosa, A. (2001). Chromohalobacter salexigens sp. nov., a moderately halophilic species that includes Halomonas elongata DSM 3043 and ATCC 33174. Int J Syst Evol Microbiol 51, 1457-1462.

Barrow, G. I. \& Feltham, R. K. A. (1993). Cowan and Steel's Manual for the Identification of Medical Bacteria, 3rd edn. Cambridge: Cambridge University Press.

Brown, M. H., Brightman, A. H., Fenwick, B. W. \& Rider, M. A. (1998). Infectious bovine keratoconjunctivitis: a review. J Vet Intern Med 12, 259-266.

De Ley, J. \& Tijtgat, R. (1970). Evaluation of membrane filter methods for DNA-DNA hybridization. Antonie van Leeuwenhoek 36, 461474.

Guindon, S. \& Gascuel, O. (2003). A simple, fast, and accurate algorithm to estimate large phylogenies by maximum likelihood. Syst Biol 52, 696-704.

Johnson, J. L. (1994). Similarity analysis of DNAs. In Methods for General and Molecular Bacteriology, pp. 655-681. Edited by P. Gerhardt, R. G. E. Murray, W. A. Wood \& N. R. Krieg. Washington, DC: American Society for Microbiology.

Juni, E. \& Bøvre, K. (2005). Genus I. Moraxella Lwoff 1939, 173, emend. Henriksen and Bøvre 1968, 391VP. In Bergey's Manual of Systematic Bacteriology, 2nd edn, vol. 2B, pp. 417-425. Edited by D. J. Brenner, N. R. Krieg, J. T. Staley \& G. M. Garrity. New York: Springer.

Kimura, M. (1980). A simple method for estimating evolutionary rates of base substitutions through comparative studies of nucleotide sequences. J Mol Evol 16, 111-120.

Kodjo, A., Tønjum, T., Richard, Y. \& Bøvre, K. (1995). Moraxella caprae sp. nov., a new member of the classical moraxellae. Int J Syst Bacteriol 45, 467-471.

Kodjo, A., Richard, Y. \& Tønjum, T. (1997). Moraxella boevrei sp. nov., a new Moraxella species found in goats. Int J Syst Bacteriol 47, 115121.

Kumar, S., Tamura, K. \& Nei, M. (2004). MEGA3: integrated software for molecular evolutionary genetics analysis and sequence alignment. Brief Bioinform 5, 150-163.

Lavin, S., Lastras, M. E., Marco, I. \& Cabañes, F. X. (2000). Report of a case of bronchopneumonia associated with Moraxella bovis isolation in a chamois (Rupicrapa pyrenaica). J Vet Med 47, 225-227.

Marmur, J. (1961). A procedure for the isolation of deoxyribonucleic acid from microorganisms. J Mol Biol 3, 208-218. 
Marmur, J. \& Doty, P. (1962). Determination of the base composition of deoxyribonucleic acid from its thermal denaturation temperature. J Mol Biol 5, 109-118.

Page, R. D. M. (1996). TreeView: an application to display phylogenetic trees on personal computers. Comput Appl Biosci 12, 357-358.

Pearson, W. R. (1994). Using the FASTA program to search protein and DNA sequence databases. Methods Mol Biol 24, 307-331.

Quinn, P. J., Carter, M. E., Markey, B. \& Carter, G. R. (1999). Moraxella species. In Clinical Veterinary Microbiology, pp. 284-286. Edited by P. J. Quinn, M. E. Carter, B. Markey \& G. R. Carter. Edinburgh, Scotland: Mosby.

Rasmussen, S. W. (1995). DNA Tools, a software package for DNA sequence analysis. Copenhagen: Carlsberg Laboratory.
Saitou, N. \& Nei, M. (1987). The neighbour-joining method: a new method for reconstructing phylogenetic trees. Mol Biol Evol 4, 406-425.

Vela, A. I., Collins, M. D., Lawson, P. A., García, N., Domínguez, L. \& Fernández-Garayzábal, J. F. (2005). Uruburuella suis gen. nov., sp. nov., isolated from clinical specimens of pigs. Int J Syst Evol Microbiol 55, 643-647.

Vela, A. I., Arroyo, E., Aragón, V., Sánchez-Porro, C., Latre, M. V., Cerdà-Cuéllar, M., Ventosa, A., Domínguez, L. \& FernándezGarayzábal, J. F. (2009). Moraxella pluranimalium sp. nov., isolated from animal specimens. Int J Syst Evol Microbiol 59, 671-674.

Wayne, L. G., Brenner, D. J., Colwell, R. R., Grimont, P. A. D., Kandler, O., Krichevsky, M. I., Moore, L. H., Moore, W. E. C., Murray, R. G. E. \& other authors (1987). International Committee on Systematic Bacteriology. Report of the ad hoc committee on reconciliation of approaches to bacterial systematics. Int J Syst Bacteriol 37, 463-464. 